\title{
1. New directions in regional economic development: an introduction
}

\author{
Roger R. Stough, Sameeksha Desai and \\ Peter Nijkamp
}

\subsection{INTRODUCTION}

The field of regional economic development has been transformed by the emergence of endogenous economic growth theory (Romer, 1986, 1990). It has unleashed a flurry of new hypotheses and related inquiries that have in turn created an exciting dynamic in the conceptual, theoretical and empirical foundations of the field. The central feature of the endogenous perspective at the local regional level is the recognition that local initiative matters in how a region grows, adapts to change and adjusts to disequilibrating physical and societal shocks. These include but are not limited to climate change and weather phenomena such as hurricanes, tsunamis and droughts, as well as other non-physical events including wars, cyclical change, new technology and paradigmatic political change. While macrolevel resource and development adjustments as always are important for adapting to such shocks, local regions make positive growth-inducing adjustments when they marshal local leadership (Stimson et al., 2009) and use local resources to plan for and drive toward a fruitful adjustment or transformative course for growth and development. It is against this contextual background that we examine some of the new directions in regional economic development.

A major tenet of endogenous growth thinking is that technical change in the first place occurs at the local regional level, thereby focusing and in fact revolutionizing the Solow (1956) seminal conclusion that technological change was the variable that accounted for the discovery that classical factors of production barely explained half of the variance in national economic growth. Because the unit of analysis for this research was at the macro level there remained an unanswered question of exactly how such change occurred. Recent theoretical and empirical research (Acs et al., 2009; Audretsch and Lehmann, 2005) has focused on the creation 
and transmission of knowledge as the front end of the technical change process and, more generally, the full commercialization of knowledge (Chesbrough et al., 2006). It seems a reasonable conclusion from this work that knowledge and its transformation into economically useful knowledge is a basic element contributing to new research in the field as it provides the key to the origins of the technical change process. We see this to be the case and thus have interpreted the significance of the contribution in terms of this accordingly.

Knowledge is produced in many ways. Universities, research centers and large corporate (public and private) organizations are primary knowledge creation centers. But these are not the only sources of new knowledge as it arises from all sorts of human contemplation and interaction including even the seemingly mundane musings of the fisherman, hiker, commuter and so on. The current time is often referred to as the knowledge age because it is a period of high knowledge creation due to recent innovations in information and communications technology (ICT) that amplify society's ability to produce it and to share it with others, regardless of the source. At the same time, knowledge in its pure form is nothing more than that, and without extensive amplification it usually fails to become economically useful. It is the amplification of knowledge that is critical for the technical change process to produce fruit. How does this amplification occur? Theory has it that it is via the entrepreneur (Acs et al., 2009). The role of the entrepreneur is to see opportunity in knowledge (Schumpeter, 1934), and good ones see opportunity where others do not (Kirzner, 1994 [1985]). The role of the entrepreneur in the technical change process is a major reason why entrepreneurship has become an intense focus of research not only in the technical change literature, but also in the field of regional science as the world of the entrepreneur exists most fully at the local regional level - the level where knowledge is created. This is yet another reason why this book holds entrepreneurship as a primary focus.

But it is not enough to recognize the leadership role of the entrepreneur in knowledge commercialization and the technical change process because there are barriers to entrepreneurial performance that vary from one region to another (and from one nation to another). So the context within which technical change and knowledge commercialization occur is not homogeneous. Acs et al. (2004) have proposed the concept of a 'knowledge filter' that, in their view, offers an explanation for the variation in the rate at which knowledge and knowledge conversion can occur, and likewise variation in the level of entrepreneurial success. The knowledge filter is that which facilitates or detracts from the ease with which both entrepreneurship and knowledge commercialization occur. If the 
filter is highly restrictive, it is difficult for knowledge to move from its raw form to that which is economically useful. A highly restrictive knowledge filter (for example where the regulatory environment is excessive, capital availability constrained, and the time to form a business is long) creates many barriers for entrepreneurship, thus inhibiting it. At the same time, if the filter is insufficient to prevent chaotic behavior or destructive entrepreneurship (Baumol, 1990), the same inhibiting or inefficient outcome is expected. The knowledge filter then is similar if not analogous to the effect of the social construct of institutional capital (Williamson, 1994): when extremely strong (or extremely weak) it creates many barriers to the process of producing economically useful knowledge and thus supporting entrepreneurial behavior. In short, the relationship between the quality of the technical change environment and the knowledge filter (also institutional quality or capital) is $\cap$ shaped. The best conditions for technical change and the entrepreneur to create economically valuable knowledge are when the knowledge filter is neither too restrictive nor too relaxed or limited.

One of the most important insights arising from endogenous growth thinking is that technical change is primarily a phenomenon of the local regional context. Viewing technical change as a local motivating phenomenon of economic development, that is in turn driven by knowledge and its transformation into economic useful knowledge (or commercial goods and services) by the entrepreneur, has created a new and enlightening dynamic in the study of regional economic development. It has elevated study of the entrepreneur from almost a non-existent status in the field to a central one in little more than a decade. Today there are a number of important questions about the role of the entrepreneur and entrepreneurship in regional economic development. A number of these are considered in the contributions to this volume. These can be grouped under several major topical areas that relate to the rise of the knowledge age as described above, and in turn to the rise of the entrepreneur in regional economic development. These are:

- The entrepreneur and their place in regional economic development.

- The role and significance of entrepreneurship in regional economic growth.

- The relationship between innovation and entrepreneurship and public policy.

- The nature and importance of knowledge and economically useful knowledge.

- Knowledge commercialization and related barriers - the knowledge filter. 
There are both theoretical and conceptual, and empirical questions embedded in each of these general topics. The entrepreneur has been conceptualized as an agent of both general social development and as an agent of the firm or business establishment. Only recently has the entrepreneur been envisioned as an agent of regional economic growth, thus the sorting out what if any overlap with the traditional factors of production exists calls for further theoretical discourse and empirical research. Entrepreneurship has a strong and sometimes confounding relation to other constructs such as leadership and innovation. It is important for the formation of public policy to understand more clearly the difference between entrepreneurship and other constructs that may have a longer lineage in the scholarly realm and may offer competing avenues for policy. Another area where some ambiguity exists is with the knowledge construct itself. For example, critical questions remain regarding how knowledge is created: by a single agent or in a more social context. However, the classical notion of proximity appears to continue to play an important role. Consequently there are questions about accessibility to knowledge (socially and physically). Accessibility is a beginning requirement for the transformation of knowledge into an economically useful form. One question in this context that has occupied the thinking of regional economic scholars is whether knowledge access is enhanced among organizations that form an industrial cluster relative to those that are not clustered. Finally, there are a large number of questions about the barriers to knowledge commercialization, that is, the process whereby raw knowledge is transformed into useful goods and services or commercialized. These focus specifically on the knowledge filter and its components that serve to constrain or accelerate its transformation and entrepreneurial success. Potential barriers of importance are: regulatory burden; availability of capital; industrial structure; special populations (advantaged or disadvantaged) such as migrants and ethnic minorities; availability of business incubation; and the role of high-intensity knowledge production environments like universities and research complexes. Various aspects of these topics and questions are addressed in the contributions to this book. At the same time, while the contributions fit into these general topical areas, they of course are not definitive. Rather, the book should be viewed as contributing to the scholarly debate that has been unfolding around the impacts of endogenous growth theory at the local regional level, and the rise of importance of knowledge and its conversion into useful goods and services.

The book is organized in two parts: theory and methods; and a set of case studies that contribute to the empirical literature and to issues of a public policy nature. 


\subsection{SUMMARY PRESENTATIONS OF THE CONTRIBUTIONS: THEORY AND METHODS}

The theory and methods contributions begin with Chapter 2 by Ronald McQuaid entitled 'The entrepreneur in economic theory'. This chapter, which observes the vast and rich literature on the entrepreneur and entrepreneurship, offers perspectives on starting a business, on being the agent owner of a venture or enterprise, and on the role of personal and/ or societal characteristics. While the richness of the construct illustrates its scope and reach, this also means that it has multiple meanings, which in turn has confused theoretical and policy debate, especially in a spatial or local regional context. McQuaid's chapter examines these different perspectives on entrepreneurship and the entrepreneur, concluding that the multiple meanings create considerable opportunity for ambiguity and contradiction when applied in a regional or spatial context. He concludes his analysis with an argument that a synthesis is needed, and proposes a $2 \times 2$ matrix model whereby the 'different' entrepreneurs are arrayed in relationship to different regional and spatial environments.

Professors John Sacco and Odd Stalebrink in Chapter 3 theoretically examine the nature of what they call 'public sector venture capitalism', or the provision by the public sector of capital for the promotion of private ventures. They identify two major sources of capital for supporting venture formation and growth: the private sector (public investment in firms and private capital); and the public sector. Market imperfection is viewed as the primary class of arguments for public sector investment in private ventures. The European Union Regional Policy and associated fund provides one illustration of a government-supplied venture fund and the problems that arise when government takes on the role of providing capital for private sector ventures. The concluding recommendation is to adopt third-party governance for public venturing projects - this may offer a partial solution to the inefficiencies that arise in such venturing, and in the extreme case where it was operated in a totally 'hands-off' or 'invisible' manner.

In Chapter 4, entitled 'Determinants and impact of entrepreneurship capital: the spatial dimension and a comparison of different econometric approaches', David Audretsch, Werner Bönte and Max Keilbach introduce the concept of entrepreneurship capital, and examine its determinants and impact. They empirically examine the construct of entrepreneurship capital using a production function analysis approach applied to regions in Germany and, while controlling for spatial effects, find that entrepreneurship contributes significantly (was statistically significant) to regional growth along with the traditional factors of production. They 
also find, and again significantly, that there is an indirect effect of 'technical knowledge' on economic growth, but through entrepreneurship. This is important because it provides some empirical supporting evidence to the claim that entrepreneurship contributes to technical knowledge conversion into growth-producing outcomes, as discussed above. The authors go on to examine these effects with respect to other growth-explaining variables and then interpret the policy implications.

In Chapter 5 Maria Teresa de Noronha Vaz examines the relationship between cooperation, innovation and location, and related policy issues. First she examines determinants of firm location and embeddedness, and relates them to innovative firm activity. Then she considers patterns of industrialization and firm governance models which are used to create a topology for coordination models. Both of these exercises are used to create a conceptual framework for the trajectory that firms follow to achieve innovation in the postmodern era. This trajectory frame begins with spatial embeddedness that in turn leads to technological learning, interfirm coordination models, and on to entrepreneurial strategies. The attributes of the different stages are explained. The trajectory frame is applied in a case study of the agro-food industry as a means to illustrate the interpretive value of this approach. The rest of the chapter explores the policy implications of the analysis and interpretive model.

Chapter 6, entitled 'Differentials in industrial structure and human capital performance across Australia's regions and the settlement system', is written by Robert Stimson. His study of recent regional trends and patterns in industrial structure and human capital, and education and occupation levels, provides a number of insights into the changing conditions in Australia's regions. This is useful in the present context in that it shows that education level - that is, quality of human capital - is rising across the country but more rapidly in metropolitan regions; that industrial structure is trending more toward technology-intensive industries; and that high-income employment is concentrating in metropolitan areas and in 'symbolic analyst' or knowledge-intensive sectors associated with the 'new economy'. Major growth dynamics tend to be concentrated in urban as opposed to more remote locations. This provides a summary of empirically grounded trends that are seen to be emerging in most of the advanced economies. Important for this book is that the stronger regional growth and development dynamics are located in urban areas, which is also the case for knowledge production, knowledge commercialization and especially technology- (knowledge-) intensive entrepreneurship.

Chapter 7 authored by Brigitte Preissl is entitled 'Innovation clusters linking regions'. Preissl examines the well-appreciated thesis that innovation-intensive firms benefit from spatial clustering, due to the ease 
of knowledge sharing that occurs in a proximal environment where firms have similar or related industrial agendas. Her analysis of knowledge transfer chains in the German automotive industry reveals that timing and quality knowledge inputs are critical for innovation, while the transfer of this knowledge into economically useful knowledge (goods and services) occurs best in environments where relations are based on trust and tacit exchange of information or knowledge. In this sense this chapter complements Chapter 5 by Maria Teresa de Noronha Vaz. A conclusion is then that access to the inputs to innovative performance is easier in a cluster than in market transactions. However, affiliated conclusions are that other non-agglomerative attributes of clusters also are important. One of these is previous or historical interaction among participating organizations, like that which occurs in industrial cluster environments.

\subsection{SUMMARIES OF THE CONTRIBUTIONS: CASE STUDIES}

Part II of the book focuses on specific issues related to facilitation of the knowledge commercialization or transfer process that are mostly empirical in nature. In each case the analysis is geographically contained in one or more regions and subregions. In short, the cases are region-specific. The importance of this is that spatially disaggregated analyses are possible, which in turn enable, in most cases, the investigator to generate specific empirically based research results.

The first chapter in Part II, Chapter 8, entitled 'Explaining China's economic growth: does entrepreneurship matter?' is by Junbo Yu, Shaoming Cheng and Roger Stough. This chapter examines two research questions: 'How does the interaction between entrepreneurship and entrepreneurship policy contribute to the form, resilience and sustainability of regional economies?' and 'What is the contribution of entrepreneurship to economic growth in transitional economies?' The contribution of entrepreneurship to economic growth among regions in China is examined, using an aggregate production function approach. The findings of this study are compatible with the work of Audretsch and Lehmann (2005). Yu, Cheng and Stough conclude from the policy perspective that: 'under certain conditions, policies focusing on enhancing entrepreneurship capital can prove to be more effective than those targeting the more traditional factors, such as labor'.

Charlie Karlsson and Kristina Nyström, using data from Swedish regions, examine 'Knowledge accessibility and new firm formation' in Chapter 9. They observe that knowledge is often concentrated in a few 
regions, much as noted in Chapter 6 by Robert Stimson with the Australia case. The huge spatial differences in knowledge in turn lead to large differences in accessibility, partly because the differences in knowledge stock are large and partly because flows of knowledge are in part spatially bounded. In short, accessing and internalizing knowledge is costly, and proximity of the source and the use of knowledge reduce the cost of technically motivated economic change. This leads to a hypothesis that there will be greater new firm formation activities in the regions with more accessibility to knowledge. The empirical investigation confirms the hypothesis along with a series of nuances and caveats.

Tüzin Baycan-Levent and Peter Nijkamp in Chapter 10 examine the driving forces, motivation and performance of migrant female entrepreneurship. The topic is examined via interpretive analysis of a serious review of the literature, and then complemented with an empirical analysis using a rough set analysis methodology of Turkish female entrepreneurs in Amsterdam, the Netherlands. Rough set analysis is useful for extracting information including decision rules from a complex multivariate data set. Because the assumptions are minimal it is also possible to work with their small but diverse sample data set. Critical success variables (rules) for producing profit and sustained development uncovered using rough set analysis include Dutch language ability, initial conditions, other entrepreneurs in the family, employment size and gender. This initial investigation produces a series of working hypotheses in the form of the rule structure of success, and concludes that further research is necessary for further testing.

Tobias Dalhammar and Terrence Brown undertake another investigation of immigrant-created enterprises in Stockholm, Sweden. This contribution, Chapter 11, examines hypotheses about the industrial effects on resource acquisition in immigrant enterprises. There has been a rapid rise of ethnic minority entrepreneurs in Sweden over the past ten or so years. As such it provokes questions not only as to why, but even more importantly about how cultural pull factors are or are not operating and, on the other hand, also structural push factors. The cultural variable operates as a pull factor in that migrants to a new country often first arrive and locate in ethnic enclaves. At the same time immigrants are usually discriminated against in the labor market, a major factor pushing them toward entrepreneurship. The authors observe that despite these generally known factors that influence or push ethnic minorities toward entrepreneurship, these do not explain the great variation found in their involvement in entrepreneurship and business activities in general. The authors recognize a third approach, called the interactive theory, which considers relationships between these and the conditions of migrant entrepreneurs' 
initial settlement upon arrival. These and other hypotheses are examined through a series of case studies ranging from involvement in ethnic services such as restaurants, to science- and technology-intensive involvement.

In Chapter 12, Peter Frank examines the question of how regions establish growth via entrepreneurship. His chapter, entitled 'The entrepreneurial environment: business incubation in the Charlotte metropolitan region' reports on this by first examining the entrepreneurial environment and then the role that business incubation provides. His examination of the environment or context in Charlotte for entrepreneurship concludes that the preconditions for entrepreneurship are minimal, that is, one would conclude that the knowledge filter in Charlotte is rather tightly meshed. He goes on to examine various incubation models that exist in the study region. A conclusion of this contribution is that a development policy to attract high-quality human capital, that is, innovative and creative workers, is an essential adjunct along with any other investments such as incubation facilities designed to attract and/or support start-up ventures.

Marina van Geenhuizen and Danny Soetanto have contributed Chapter 13, entitled 'University spin-offs: an exploration of age-patterns of obstacles to growth'. The Bayh-Dole Act in the US in the mid-1980s spurred universities to develop technology transfer programs that often involved technology- or knowledge-specialized business start-ups that were spinoffs of university research. The trend to form such programs did not end in the US, but in the 2000s spread to other continents. In this chapter Geenhuizen and Soetanto examine the factors that influence the success of such university-based ventures at different stages of development. Their analysis is based on a sample of some 43 spin-offs at the Delft University of Technology. The empirical analysis finds that early-stage university-based ventures have better ability to solve and prevent problems than those in later stages of development (three or four years on). Based on these findings, the authors offer alternative models for preventing and solving such problems, especially for highly innovative and often technologyintensive ventures. Quantitative and interpretive analysis provide design guidance for transforming existing incubation policies for university spin-offs.

The final contribution, Chapter 14 by Börje Johansson and Hans Lööf, examines the inflows of foreign direct investment (FDI) to Sweden and its consequences for innovation and renewal at the local regional level. This research is empirical and uses a firm-specific data set (2086 firms) to examine innovativeness and the ability to renew firm-level competitiveness. Four classes of firms are created out of the data set, with one end of this classification spectrum being uninational and the other transnational firms. The research, using a variety of descriptive statistical data and 
regression modeling, finds that uninational firms are less integrated than all the other more open firm classes in a variety of forms of innovative collaboration, and that uninationals have fewer product and process innovations and exhibit lower levels of non-imitation innovations. In short, FDI coming from the transnational context promotes greater innovativeness in the case of Sweden. The policy implications are reasonably obvious for Sweden's economic development and growth, and it is not unreasonable to assume ceteris paribus that the findings for Sweden are similar to what one would find in other countries. However a caveat may exist in that the small size of Sweden's home market, and rules governing industry structure, may counter, in part, generalizing the findings obtained for Sweden.

\section{REFERENCES}

Acs, A., D. Audretsch, P. Braunerhjelm and B. Carlsson (2004), 'The missing link: the knowledge filter and entrepreneurship in endogenous growth', Discussion Paper no. 4783, London: Centre for Economic Policy Research.

Acs, Z., P. Braunerhjelm, D. Audretsch and B. Carlsson (2009), 'The knowledge spillover theory of entrepreneurship', Small Business Economics, 32, 15-30.

Audretsch, D. and E. Lehmann (2005), 'Does the knowledge spillover theory of entrepreneurship hold for regions?' Research Policy, 34, 1191-1202.

Baumol, W.J. (1990), 'Entrepreneurship: productivity, unproductive, and destructive', Journal of Political Economy, 98(5), 893-921.

Chesbrough, H., W. Vanhaverbeke and J. West (eds) (2006), Open Innovation: Researching a New Paradigm, Oxford: Oxford University Press.

Kirzner, J. (1994), 'The entrepreneur in economic theory', in E. Dahmen, L. Hannah and I.M. Kirzner (eds), The Dynamics of Entrepreneurship, Lund: Lund University Press, pp. 146-74. First published 1985, Crafoord Lectures No. 5.

Romer, P. (1986), 'Increasing returns and long run growth', Journal of Political Economy, 94, 1002-37.

Romer, P.M. (1990), 'Endogenous technological change', Journal of Political Economy, 98, S71-S102.

Schumpeter, J.A. (1934), The Theory of Economic Development, Cambridge, MA: Harvard University Press.

Solow, R.M. (1956), 'A contribution to the theory of economic growth', Quarterly Journal of Economics, 70, 65-94.

Stimson, R., R. Stough and M. Salazar (2009), Leadership and Institutions in Regional Endogenous Development, Cheltenham, UK and Northampton, MA, USA: Edward Elgar Publishing.

Williamson, O.E. (1994), Institutions and Economic Organization: The Governance Perspective, Washington, DC: World Bank. 